\title{
Samchuleum attenuates diabetic renal injury through the regulation of TGF- $\beta /$ Smad signaling in human renal mesangial cells
}

\author{
JUNG JOO YOON ${ }^{1,2^{*}}$, YUN JUNG LEE ${ }^{1,2^{*}}$, SEUNG NAMGUNG ${ }^{1,2}$, \\ BYUNG HYUK HAN ${ }^{1,2}$, EUN SIK CHOI ${ }^{1,2}$, DAE GILL KANG ${ }^{1,2}$ and HO SUB LEE ${ }^{1,2}$ \\ ${ }^{1}$ College of Oriental Medicine and Professional Graduate School of Oriental Medicine, Wonkwang University, \\ Iksan, Jeonbuk 540-749; ${ }^{2}$ Hanbang Cardio-Renal Syndrome Research Center, College of Oriental Medicine, \\ Wonkwang University, Iksan, Jeonbuk 54538, Republic of Korea
}

Received June 22, 2016; Accepted February 27, 2017

DOI: $10.3892 / \mathrm{mmr} .2017 .8201$

\begin{abstract}
Renal mesangial cell proliferation is a major clinical feature of diabetic nephropathy (DN) and includes glomerulosclerosis and renal fibrosis. Samchuleum (SCE) is a traditional herbal mixture that is recorded in the ancient Korean medical book, Donguibogam. The present study attempted to determine whether SCE treatment was able to improve high glucose (HG)-induced mesangial cell fibrosis and glomerulosclerosis in primary cultured human mesangial cells. Thymidine incorporation under HG induction was increased, but was decreased by SCE in a dose dependent manner. Pretreatment with SCE led to a downregulation in the expression of cyclins and cyclin-dependent kinases (CDKs), and an upregulation of the CDK inhibitors, $\mathrm{p} 21^{\text {wafl/cipl }}$ and $\mathrm{p} 27^{\mathrm{kip} 1}$. In addition, SCE exposure markedly suppressed the reactive oxygen species signaling pathway under HG conditions. HG enhanced the expression levels of fibrosis-promoting mediators, including collagen IV and connective tissue growth factor, which were markedly attenuated by SCE. SCE treatment inhibited HG-induced fibronectin mRNA expression and decreased the expression of transforming growth factor (TGF)- $\beta 1$, Smad-2 and Smad-4, whereas Smad-7 expression increased under HG. SCE treatment induced the degradation of the extracellular matrix by blocking TGF- $\beta 1 /$ Smad signaling. Therefore, the present study suggested that the inhibitory effect of SCE on
\end{abstract}

Correspondence to: Professor Ho Sub Lee or Dr Dae Gill Kang, College of Oriental Medicine and Professional Graduate School of Oriental Medicine, Wonkwang University, 460 Iksandae-ro, Iksan, Jeonbuk 540-749, Republic of Korea

E-mail: host@wku.ac.kr

E-mail: dgkang@wku.ac.kr

*Contributed equally

Key words: samchuleum, mesangial cell, fibrosis, transforming growth factor- $\beta 1$, diabetic nephropathy mesangial proliferation and renal fibrosis may be an effective therapy in the treatment of renal dysfunction leading to DN.

\section{Introduction}

Diabetic nephropathy (DN) is a common end-stage renal disease that is characterized by mesangial cell proliferation and extracellular matrix (ECM) accumulation with mesangial expansion, glomerular hypertrophy, tubulointerstitial fibrosis and glomerular sclerosis in later stages (1-3). Mesangial cell proliferation is one of the major pathological characteristics in the early stage of DN (4-6). The expression of a number of cyclin-dependent kinase (CDK) inhibitors may also downregulate progressive glomerular hypertrophy (7).

Mesangial cells are hypothesized to serve an important role in the metabolism of type IV collagen. Regulation of type IV collagen may result in ECM expansion, leading to mesangial lesion hypercellularity (8). High-glucose (HG) cell culture conditions induce mesangial cells to overexpress ECM proteins $(9,10)$. Increased generation of reactive oxygen species (ROS) is a mark of the diabetic environment, and studies have demonstrated that ROS induce the production of profibrotic growth factors, including transforming growth factor (TGF) $\beta$ and type IV collagen $(11,12)$. Connective tissue growth factor (CTGF) expression may lead to diabetic renal disease by inducing ECM synthesis and inhibiting ECM degradation. In renal mesangial cells, HG-induced ECM degradation occurs through changes in the expression levels of the matrix metalloproteinases (MMPs) and their specific inhibitors, the tissue inhibitors of MMPs (TIMP-1 and TIMP-2) (13). A previous study reported that TIMP-2 can bind to MMP-2 and membrane-bound type 1 (MT1)-MMP, and it has been demonstrated to be upregulated in diabetic conditions (14). In addition, CTGF has been reported to mediate the effects of HG in the inhibition of mesangial matrix expansion, via increasing the expression of TIMPs (15).

TGF- $\beta$ is the most potent and ubiquitous profibrogenic cytokine, and serves an important role in the mechanisms underlying mesangial cell hypertrophy and fibrotic/sclerotic manifestations of DN $(16,17)$. The TGF- $\beta /$ Smad signaling 
pathway is crucial for profibrogenic cellular responses. Active TGF- $\beta$ binds to a TGF- $\beta$ type II receptor on the cell membrane, which activates a type I receptor, leading to the subsequent activation of receptor-regulated Smads (R-Smads), such as Smad-2 and Smad-3. The phosphorylated (p)-R-Smads form a complex with the common mediator-Smad (Smad-4), which translocates into the nucleus to regulate gene transcription by binding to the Smad binding element in the promoter of the target genes (18). Conversely, the inhibitory Smads (I-Smads, Smad- 6 and Smad-7) negatively regulate TGF- $\beta$ signaling by binding to a type I receptor or by activating Smad signaling. I-Smads have been revealed to antagonize TGF- $\beta$-mediated signaling through various mechanisms. Smad7 has been reported to form a stable complex with TGF- $\beta$ type I receptors, thus leading to the inhibition of R-Smad phosphorylation and hetero-complex formation between R-Smads and Smad-4 (19).

Nuclear factor (NF)- $\kappa \mathrm{B}$ is a transcription factor that regulates the initiation and termination of inflammation. Activation of NF- $\kappa \mathrm{B}$ by hyperglycemia has been implicated in the pathogenesis of diabetes and the associated complications of DN (20). $\mathrm{NF}-\kappa \mathrm{B}$ is maintained in an inactive form in the cytoplasm by binding to the inhibitor of $\mathrm{NF}-\kappa \mathrm{B}(\mathrm{I} \kappa \mathrm{B})$ protein $(21)$. In diabetes, activated NF- $\kappa \mathrm{B}$ translocates into the nucleus and induces the expression of proinflammatory factors, including intercellular adhesion molecule (ICAM)-1, monocyte chemotactic protein (MCP)-1 and TGF- $\beta 1$, which in turn induces persistent and enhanced inflammation, fibronectin overproduction and ECM accumulation, and finally leads to accelerated renal injury, including glomerulosclerosis and renal fibrosis (22).

Samchuleum (SCE) was originally recorded in the ancient Korean medical book, Donguibogam, and is a well-known traditional blended herbal formula specifically used for dysuria caused by a shifted bladder in pregnant woman. SCE is composed of nine dried herbs: Rehmannia glutinosa, Paeonia lactiflora, Cnidium officinale Makino, Angelica sinensis, Panax japonicus, Atractylodes ovata, Pinellia ternata, Citrus reticulata and Glycyrrhiza glabra. However, the protective effects of SCE on renal dysfunction have not previously been studied, to the best of our knowledge. Therefore, the present study attempted to determine whether SCE is able to prevent HG-induced mesangial cell fibrosis and glomerulosclerosis in primary human mesangial cell cultures.

\section{Materials and methods}

Preparation of a water extract of SCE. The formula for SCE consists of nine herbs, including: Rehmanniae Radix Preparata [Rehmannia glutinosa (Gaertn.) DC; rhizome, steamed and dried]; Paeoniae Radix (Paeonia lactiflora Pall; root), Cnidii Rhizoma (Cnidium officinale Makino; rhizome); Angelicae Gigantis Radix [Angelica sinensis (Oliv.) Diels; root]; Ginseng Radix (Panax japonicus C.A. Meyer; root); Atractylodis Rhizoma Alba [Atractylodes ovata (Thunb.) DC; root]; Pinelliae Rhizoma [Pinellia ternata (Thunb.) Breit; tuberous root]; Citri Pericarpium (Citrus reticulata Blanco; pericarp); and Glycyrrhizae Radix (Glycyrrhiza glabra L.; root). These were mixed in equal weights (30 g) and placed in a 51 conical flask. The mixed sample $(270 \mathrm{~g})$ was boiled with 21 distilled water for $2 \mathrm{~h}$ at $100^{\circ} \mathrm{C}$ and then centrifuged at $990 \mathrm{x} \mathrm{g}$ for $20 \mathrm{~min}$ at $4^{\circ} \mathrm{C}$. The supernatant was filtered with
Whatman no. 3 filter papers (Whatman; GE Healthcare Life Sciences, Chalfont, UK), and then concentrated using a rotary evaporator. The concentrated supernatant was lyophilized to produce a powder $(44.92 \mathrm{~g})$, which was then stored at $-70^{\circ} \mathrm{C}$ until use. A herbarium voucher specimen (Samchuleum; cat. no. HBG192-01) was deposited in Hanbang Body-fluid Research Center, Wonkwang University (Jeonbuk, Korea).

Mesangial cell cultures. Human renal mesangial cells (HRMC; cat. no. 4200) were purchased from ScienCell Research Laboratories, Inc. (Carlsbad, CA, USA). Mesangial cells were cultured in Mesenchymal Stem Cell Medium (ScienCell Research Laboratories, Inc.), and incubated in a humidified (50-70\%) $\mathrm{CO}_{2}$ incubator at $37^{\circ} \mathrm{C}$ under $95 \%$ air and $5 \% \mathrm{CO}_{2}$. Cells between passages three and seven were employed in the present study.

Measurement of cell proliferation. $\left[{ }^{3} \mathrm{H}\right]$-thymidine incorporation was performed to examine the effects of SCE on renal mesangial cell proliferation. Mesangial cells were incubated in a 24-well plate until $70 \%$ confluent and subsequently treated with glucose $(25 \mathrm{mM})$ and SCE $(10-50 \mu \mathrm{g} / \mathrm{ml})$, followed by the addition of $1 \mu \mathrm{Ci}$ of $\left[{ }^{3} \mathrm{H}\right]$-thymidine [methyl- $\left({ }^{3} \mathrm{H}\right)$ thymidine $50 \mathrm{Ci} / \mathrm{mM}$; Nycomed; Takeda Pharmaceuticals International $\mathrm{GmbH}$, Zurich, Switzerland]. Following incubation at $37^{\circ} \mathrm{C}$ for $24 \mathrm{~h}$, the plate was washed once with ice-cold PBS ( $\mathrm{pH} 7.4$ ), treated 3 times with $10 \%$ trichloroacetic acid $(2 \mathrm{ml})$ for $5 \mathrm{~min}$ each time, and then lysed in $0.3 \mathrm{~N} \mathrm{NaOH}(1 \mathrm{ml})$ and $1 \%$ SDS for at least $30 \mathrm{~min}$ at room temperature. Following lysis, $\left[{ }^{3} \mathrm{H}\right]$-thymidine activity was measured using the Beckman LS 7500 Liquid Scintillation Counter (Beckman Coulter, Inc., Brea, CA, USA) and the resulting data were analyzed using the software provided by the manufacturer. Each experiment was performed in triplicate or quadruplicate.

Western blot analysis. Human mesangial cells were were pretreated with SCE for $30 \mathrm{~min}$ and then stimulated with HG for $24 \mathrm{~h}$. Subsequently, cells were lysed using ice-cold lysis buffer with freshly added protease inhibitor cocktail (Amresco, LLC, Solon, OH, USA) at $4^{\circ} \mathrm{C}$ for $30 \mathrm{~min}$, centrifuged at $14,000 \mathrm{x} \mathrm{g}$ at $4^{\circ} \mathrm{C}$ for $10 \mathrm{~min}$ and the supernatants were collected. Protein concentration was measured using a Bradford assay with bovine serum albumin (BSA) as the standard. Equal amounts of protein samples $(40 \mu \mathrm{g})$ were separated by $10 \%$ SDS-PAGE and transferred onto nitrocellulose membranes. Membranes were blocked with $5 \%$ skimmed milk powder in TBS containing $0.05 \%$ Tween-20 [10 mM Tris- $\mathrm{HCl}$ (pH 7.6), $150 \mathrm{mM} \mathrm{NaCl}, 0.05 \%$ Tween-20] and incubated overnight at $4^{\circ} \mathrm{C}$ with the appropriate primary antibodies (Table I). The primary antibodies were detected with the corresponding horseradish peroxidase-conjugated secondary antibodies (1:5,000; Table I). Protein bands were visualized using Enhanced Chemiluminescence Detection Reagent (Amersham; GE Healthcare Life Sciences) with the Chemi-doc image analyzer (Bio-Rad Laboratories, Inc., Hercules, CA, USA). $\beta$-actin was used as the loading control. Lamin B was used as the loading control for nuclear proteins. Blots were semi-quantified by densitometric analysis using the Image J software version $1.49 \mathrm{v}$ (National Institutes of Health, Bethesda, MD, USA). 
Preparation of cytoplasmic and nuclear extracts. Renal mesangial cells $\left(8.8 \times 10^{6}\right.$ cells) were rapidly harvested in cold PBS on ice by sedimentation and centrifuged at $10,000 \mathrm{x}$ g for $10 \mathrm{~min}$ at $4^{\circ} \mathrm{C}$. Cytoplasmic and nuclear extracts were prepared using the Nuclear Extract kit (Active Motif, Inc., Carlsbad, CA, USA), according to the manufacturer's protocol. Briefly, cells were scraped, washed with PBS, resuspended in hypotonic buffer (10 mM HEPES, $1.5 \mathrm{mM} \mathrm{MgCl}_{2}, 10 \mathrm{mM} \mathrm{KCl}$, $0.2 \mathrm{mM}$ phenylmethylsulfonyl fluoride and $0.5 \mathrm{mM}$ dithiothreitol), incubated on ice for $15 \mathrm{~min}$, and then lysed by adding $1 \%$ detergent, followed by vigorous vortexing for $10 \mathrm{sec}$ and centrifugation at $4^{\circ} \mathrm{C}$ for $30 \mathrm{sec}$ at $14,000 \times \mathrm{g}$. The nuclear pellet was resuspended in $30 \mu 1$ of complete lysis buffer (1 mm DTT, $1 \%$ protease inhibitor cocktail, lysis buffer AM1). Nuclear proteins were extracted by gentle agitation on ice for $30 \mathrm{~min}$ and centrifugation at $4^{\circ} \mathrm{C}$ for $10 \mathrm{~min}$ at $14,000 \mathrm{x} \mathrm{g}$. Subsequently, the extracts were immediately transferred to clean screw-cap tubes and stored at $-80^{\circ} \mathrm{C}$ until use.

RNA isolation and reverse transcription-quantitative polymerase chain reaction $(R T-q P C R)$. RNA isolation from cultured mesangial cells $\left(6 \times 10^{6}\right)$ was performed using an RNeasy Plus Mini kit (Qiagen GmbH, Hilden, Germany). RNA $(1 \mu \mathrm{g})$ quality was measured at the optical density ratio 260/280 nm by using a UV-spectrophotometer. cDNA was synthesized using an HiPi RT-PCR kit (ELPIS-Biotech. Inc., Daejeon, Korea). RT-qPCR analysis was performed using the StepOnePlus Real-Time PCR system (Applied Biosystems; Thermo Fisher Scientific, Inc., Waltham, MA, USA) and optimized with DyNAmo SYBR-Green 2-step RT-qPCR kit protocol (Finnzymes; Thermo Fisher Scientific, Inc.). qPCR was initiated by activating the AmpliTaq DNA polymerase by hot start at $95^{\circ} \mathrm{C}$ for $15 \mathrm{~min}$ followed by 40 cycles of denaturation at $94^{\circ} \mathrm{C}$ for $20 \mathrm{sec}$, annealing at $60^{\circ} \mathrm{C}$ for $30 \mathrm{sec}$, extension at $72^{\circ} \mathrm{C}$ for $60 \mathrm{sec}$, and plate reading at $60^{\circ} \mathrm{C}$ for $10 \mathrm{sec}$. The temperature of PCR products was increased from 65 to $95^{\circ} \mathrm{C}$ at a rate of $0.2^{\circ} \mathrm{C} / \mathrm{sec}$ and the resulting data were analyzed by using the StepOne ${ }^{\mathrm{TM}}$ software version 2.3 provided by the manufacturer. The PCR products were resolved by $1 \%$ agarose gel electrophoresis and visualized using ethidium bromide (EMD Millipore, Billerica, MA, USA) to a final concentration of $\sim 0.5 \mu \mathrm{g} / \mathrm{ml}$. The primers used in the present study are presented in Table II. Experiments were performed in triplicate and mRNA expression was normalized to GAPDH. Gene expression was quantified using the $2^{-\Delta \Delta \mathrm{Cq}}$ method, as previously described (23).

Immunofluorescence microscopy assay. Renal mesangial cells $\left(3 \times 10^{6}\right)$ were fixed with $4 \%$ paraformaldehyde at room temperature for $30 \mathrm{~min}$ in the culture dishes and permeabilized with $0.4 \%$ Triton X-100 in PBS at room temperature for 5 min. Samples were blocked with $1 \%$ BSA (Santa Cruz Biotechnology, Inc., Dallas, TX, USA) for $30 \mathrm{~min}$ at room temperature and incubated with anti-Smad 2 and anti-NF- $\kappa \mathrm{B}$ subunit p65 primary antibodies (Table I) at $4^{\circ} \mathrm{C}$ overnight. Samples were then incubated with secondary antibodies labeled with Alexa Fluor 488 (cat. no. A-11001; 1:200; Molecular Probes; Thermo Fisher Scientific, Inc.) for $60 \mathrm{~min}$ at room temperature. Nuclei were counterstained with $1 \mu \mathrm{g} / \mathrm{ml}$ DAPI at room temperature for $5 \mathrm{~min}$. The images were captured using an Eclipse Ti fluorescence microscope (Nikon Corporation, Tokyo, Japan) and analyzed using ImagePro software version 5.0 (Media Cybernetics, Inc., Rockville, MD, US).

Luciferase promoter assay. Cells at 60-70\% confluence were transiently co-transfected with the plasmids according to the Lipofectamine LTX kit (Invitrogen; Thermo Fisher Scientific, Inc., Carlsbad, CA) and the manufacturer's plasmid transfection protocol. Plasmids linked to a luciferase reporter (MMP-2 promoter) were kindly provided from Dr Lee ST (Yonsei University, Seoul, Republic of Korea). The plasmid mixture containing $5 \mu \mathrm{g}$ of the MMP-2-promoter-luciferase reporter or the Renilla-luciferase reporter and $5 \mu \mathrm{l}$ of Opti-MEM ${ }^{\mathrm{TM}}$ Media (Thermo Fisher Scientific, Inc.) was blended with the Lipofectamine LTX reagent. Following incubation for $48 \mathrm{~h}$ at $37^{\circ} \mathrm{C}$, the cells were pretreated with SCE for $30 \mathrm{~min}$ and $25 \mathrm{mM}$ D-glucose (HG) was added for $24 \mathrm{~h}$. Cells in the control group were cultured with $5.4 \mathrm{mmol} / 1$ glucose at $37^{\circ} \mathrm{C}$. Cells were then lysed with $100 \mu \mathrm{l}$ of reporter lysis buffer and the extracts $(30 \mu \mathrm{l})$ were used to assess luciferase activity using the Pierce $^{\mathrm{TM}}$ Renilla-Firefly Luciferase Dual Assay kit (Thermo Fisher Scientific, Inc.), as previously described (24). Luciferase activity was normalized to Renilla activity and expressed as a percentage of the control.

Intracellular ROS production analysis. A fluorescent dye (5,6-chloromethyl-2',7'-dichlorodihydrofluorescein diacetate; $\mathrm{CM}-\mathrm{H}_{2}$ DCFDA) was used to examine the intracellular generation of ROS. Renal mesangial cells ( $70 \%$ confluent) in 96-well plates were pretreated with $\operatorname{SCE}(10-50 \mu \mathrm{g} / \mathrm{ml})$ or $\mathrm{N}$-acetyl-L-cysteine (NAC; $1 \mathrm{mM}$ ) for $30 \mathrm{~min}$ and then stimulated with $\mathrm{HG}(25 \mathrm{mM})$ for $24 \mathrm{~h}$ at $37^{\circ} \mathrm{C}$. Following incubation, $2 \mu \mathrm{M} \mathrm{CM}-\mathrm{H}_{2} \mathrm{DCFDA}$ were added for $30 \mathrm{~min}$ at $37^{\circ} \mathrm{C}$. The fluorescence intensity was measured with an Infinite F200 PRO Spectrofluorometer (Tecan Group Ltd., Männedorf, Switzerland) and cells were observed under an Eclipse Ti fluorescence microscope (Nikon Corporation). Recording and analysis of fluorescence signals was performed using the NIS-Elements Basic Research Microscope Imaging software version 4.30.00 (Nikon Corporation).

Statistical analysis. All experiments were repeated at least three times. The results are presented as the mean \pm standard error of the mean, and the data were analyzed using one-way analysis of variance followed by a Dunnett's test or Student's t-test to decide any significant differences. $\mathrm{P}<0.05$ was considered to indicate a statistically significant difference.

\section{Results}

Effects of SCE on HG-induced mesangial cell proliferation. To investigate the effects of SCE on HG-induced renal mesangial cell proliferation, $\left[{ }^{3} \mathrm{H}\right]$-thymidine incorporation was measured. As demonstrated in Fig. 1A, the $\left[{ }^{3} \mathrm{H}\right]$-thymidine incorporation assay revealed that the $\mathrm{HG}$-induced increase in cell proliferation was significantly inhibited by pretreatment with $20-50 \mu \mathrm{g} / \mathrm{ml} \mathrm{SCE}(\mathrm{P}<0.01)$. HG treatment also resulted in the increased expression of CDK-2 or CDK-4, cyclin D1 and cyclin $\mathrm{E}$ proteins and the decreased expression levels of $\mathrm{CDK}$ 
Table I. Primary and secondary antibodies used in the present study.

\begin{tabular}{|c|c|c|c|}
\hline Antibody & Supplier & Catalogue number & Dilution \\
\hline \multicolumn{4}{|l|}{ Primary } \\
\hline CDK2 (H-298) & Santa Cruz Biotechnology, Inc. (Dallas, TX, USA) & sc-748 & $1: 1,000$ \\
\hline CDK4 (H-22) & Santa Cruz Biotechnology, Inc. (Dallas, TX, USA) & sc-601 & $1: 1,000$ \\
\hline Cyclin D1 (A-12) & Santa Cruz Biotechnology, Inc. (Dallas, TX, USA) & sc-8396 & $1: 1,000$ \\
\hline Cyclin E (HE12) & Santa Cruz Biotechnology, Inc. (Dallas, TX, USA) & sc-247 & $1: 1,000$ \\
\hline TGF- $\beta 1(\mathrm{~V})$ & Santa Cruz Biotechnology, Inc. (Dallas, TX, USA) & sc-146 & $1: 1,000$ \\
\hline p-Smad-2 (Ser465/467) & EMD Millipore (Billerica, MA, USA) & AB3849-I & $1: 1,000$ \\
\hline Smad-2 (S-20) & Santa Cruz Biotechnology, Inc. (Dallas, TX, USA) & sc-6200 & $1: 1,000$ \\
\hline Smad-4 (B-8) & Santa Cruz Biotechnology, Inc. (Dallas, TX, USA) & sc-7966 & $1: 1,000$ \\
\hline Smad-7 (H-79) & Santa Cruz Biotechnology, Inc. (Dallas, TX, USA) & sc-11392 & $1: 1,000$ \\
\hline MT1-MMP (V-16) & Santa Cruz Biotechnology, Inc. (Dallas, TX, USA) & sc-12366 & $1: 1,000$ \\
\hline TIMP-2 (3A4) & Santa Cruz Biotechnology, Inc. (Dallas, TX, USA) & sc-21735 & $1: 1,000$ \\
\hline Collagen IV (H-57) & Santa Cruz Biotechnology, Inc. (Dallas, TX, USA) & sc-135231 & $1: 1,000$ \\
\hline CTGF (B-6) & Santa Cruz Biotechnology, Inc. (Dallas, TX, USA) & sc-373936 & $1: 1,000$ \\
\hline ICAM-1 (H-108) & Santa Cruz Biotechnology, Inc. (Dallas, TX, USA) & sc-7891 & $1: 1,000$ \\
\hline MCP-1 (R-17) & Santa Cruz Biotechnology, Inc. (Dallas, TX, USA) & sc-1785 & $1: 1,000$ \\
\hline NF-кB p65 (F-6) & Santa Cruz Biotechnology, Inc. (Dallas, TX, USA) & sc-8008 & $1: 1,000$ \\
\hline $\mathrm{I}-\kappa \mathrm{B}-\alpha(\mathrm{C}-15)$ & Santa Cruz Biotechnology, Inc. (Dallas, TX, USA) & sc-203 & $1: 1,000$ \\
\hline$\beta$-actin $(4 \mathrm{E} 8 \mathrm{H} 3)$ & Santa Cruz Biotechnology, Inc. (Dallas, TX, USA) & sc-130065 & $1: 1,000$ \\
\hline \multicolumn{4}{|l|}{ Secondary } \\
\hline Goat anti-mouse IgG & Enzo Life Sciences, Inc. (Farmingdale, NY, USA) & ADI-SAB-100 & $1: 5,000$ \\
\hline Goat anti-rabbit IgG & Enzo Life Sciences, Inc. (Farmingdale, NY, USA) & ADI-SAB-300 & $1: 5,000$ \\
\hline Mouse anti-sheep/goat IgG & Enzo Life Sciences, Inc. (Farmingdale, NY, USA) & ADI-SAB-400 & $1: 5,000$ \\
\hline
\end{tabular}

CDK, cyclin-dependent kinase; TGF, transforming growth factor; p-, phosphorylated; MT1-MMP, membrane-bound type 1 matrix metalloproteinase; TIMP, tissue inhibitor of MMP; CTGF, connective tissue growth factor; ICAM, intercellular adhesion molecule; MCP, monocyte chemotactic protein; NF, nuclear factor; I, inhibitor; Ig, immunoglobulin.

inhibitory proteins $\mathrm{p} 21^{\mathrm{waf} 1 / \mathrm{cip} 1}$ and $\mathrm{p} 27^{\mathrm{kip} 1}$ (Fig. 1B). By contrast, exposure to SCE reduced the expression levels of cell-cycle regulated proteins (Fig. 1B). Therefore, it was demonstrated that SCE treatment reduced HG-induced mesangial cell proliferation through the downregulation of the expression of cell cycle regulatory factors.

Effects of SCE on HG-induced TGF- $\beta 1 /$ Smad signaling pathway. The present study investigated whether SCE treatment was able to reverse $\mathrm{HG}$-induced renal mesangial cell fibrosis through the regulation of TGF- $\beta /$ Smad signaling. Western blot analysis revealed that $\mathrm{HG}$ stimulation enhanced the protein expression of TGF- $\beta 1, \mathrm{p}-\mathrm{Smad}-2$ and Smad-4, whereas SCE co-administration appeared to prevent this effect (Fig. 2A). In addition, HG stimulation enhanced the nuclear expression of p-Smad-2 protein, whereas SCE $(20-50 \mu \mathrm{g} / \mathrm{ml})$ reduced $\mathrm{p}-\mathrm{Smad}-2$ protein expression, particularly in the nuclear extracts. Conversely, cytoplasmic Smad-7 protein expression was increased by SCE co-treatment. PCR and RT-qPCR analyses revealed that the HG-induced TGF- $\beta 1$, Smad-2 and Smad-4 mRNA levels were decreased following co-treatment with SCE (Fig. 2B). As demonstrated in Fig. 3, HG-stimulated mesangial cells exhibited increased staining intensities of p-Smad-2 in the nucleus. Nuclear p-Smad-2 expression levels were decreased following treatment with
SCE in dose-dependent manner. As TGF- $\beta$ signaling acts through Smad-2 and Smad-4, these results demonstrated that SCE may block TGF- $\beta$-mediated fibrosis by interrupting downstream Smad signaling.

Effects of SCE on MMP2 activation and collagenIV expression. MMP-2 activity was measured by luciferase reporter assay. As demonstrated in Fig. 4A, pretreatment with SCE reversed the $\mathrm{HG}$-induced decrease in MMP-2 promoter activity in human renal mesangial cells. MT1-MMP has been revealed to activate MMP-2 in a process that requires TIMP-2, thereby degrading ECM (25); therefore, the effects of SCE treatment on the expression of MT1-MMP and TIMP-2 in HG-treated mesangial cells were investigated. Pretreatment with $\geq 20 \mu \mathrm{g} / \mathrm{ml} \mathrm{SCE}$ upregulated the HG-inhibited MT1-MMP expression, whereas the HG-induced expression of TIMP-2 was downregulated following pretreatment with SCE (Fig. 4A).

The inhibitory effects of SCE on HG-induced mesangial matrix expansion were investigated by examining the levels of collagen IV and CTGF protein expression levels by western blotting (Fig. 4B). The expression of collagen IV was elevated by $\mathrm{HG}$ stimulation, and this increase in expression was reduced when cells were pretreated with $\geq 10 \mu \mathrm{g} / \mathrm{ml}$ SCE. SCE inhibited the HG-induced expression CTGF protein in renal mesangial cells. PCR analysis confirmed that SCE treatment 
Table II. Primers (forward and reverse) used for reverse transcription-quantitative polymerase chain reaction.

\begin{tabular}{ll}
\hline Gene & \multicolumn{1}{c}{ Primer } \\
\hline TGF- $\beta 1$ & F: 5'-GCA CGT GGA GCT GTA CCA-3' \\
& R: 3'-CAG CCG GTT GCT GAG GTA-5' \\
Collagen IV & F: 5'-TGT CAG CAA TTA GGC AGG TC-3' \\
& R: 3'-CAC CAT GTT TCG GAA TGG TT-5' \\
CTGF & F: 5'-CTG CAG GCT AGA GAA GCA GAG-3' \\
& R: 3'-GAT GCA CTT TTT GCC CTT CT-5' \\
ICAM-1 & F: 5'-GGC CGG CCA GCT TAT ACA C-3' \\
& R: 3'-TAG ACA CTT GAG CTC GGG CA-5' \\
MCP-1 & F: 5'-ACT GAA GCT CGT ACT CTC-3' \\
& R: 3'-CTT GGG TTG TGG AGT GAG-5' \\
GAPDH & F: 5'-CAA GGC TGA GAA TGG GAA GC-3' \\
& R: 3'-AGC ATG TGG GAA CTC AGA TC-5'
\end{tabular}

F, Forward; R, Reverse; TGF, transforming growth factor; CTGF, connective tissue growth factor; ICAM, intercellular adhesion molecule; MCP, monocyte chemotactic protein.

affected the HG-triggered expression levels of collagen IV and CTGF (Fig. 4C). Collagen IV and CTGF mRNA expression levels were markedly reduced by pretreatment with $\geq 20 \mu \mathrm{g} / \mathrm{ml}$ SCE in HG-exposed cells. The present results demonstrated that treatment with SCE inhibited the mRNA and protein expression of collagen IV, and decreased CTGF production. These results demonstrated that SCE treatment has the potential to block HG-induced glomerulosclerosis and kidney fibroblast.

Effects of SCE on HG-stimulated inflammation. The present study suggested that SCE might alleviate mesangial inflammation in the renal fibrogenetic process. ICAM-1 has been reported to promote the infiltration of inflammatory cells, including mononuclear macrophages, into glomeruli and kidney interstitial cells; inflammation-related factors, such as ICAM-1, are known to accelerate glomerulosclerosis caused by diabetes (26). SCE treatment inhibited the HG-induced expression of ICAM-1 and MCP-1 proteins (Fig. 5A). In addition, ICAM-1 and MCP-1 mRNA levels were also reduced by $20-50 \mu \mathrm{g} / \mathrm{ml} \mathrm{SCE}$ pretreatment in HG-exposed mesangial cells, as evidenced by PCR and RT-qPCR (Fig. 5A). The present study hypothesized that SCE treatment may alleviate renal inflammatory response related to the renal fibrotic process.

Activated NF- $\mathrm{kB}$ translocates to the nucleus where it binds to target gene promoters to trigger the transcription of genes associated with the inflammatory response (27); this subsequently promotes mesangial cell proliferation and mononuclear cell infiltration, and eventually accelerates glomerulosclerosis in diabetes. Western blot analysis revealed that $\mathrm{HG}$ exposure caused NF-kB subunit p65 nuclear translocation, which was suppressed by pretreatment with SCE (Fig. 5B). In addition, SCE treatment reduced the HG-induced phosphorylation of IкB- $\alpha$ in the cytoplasm. Immunofluorescence cell staining demonstrated that p65 was expressed at low levels in the
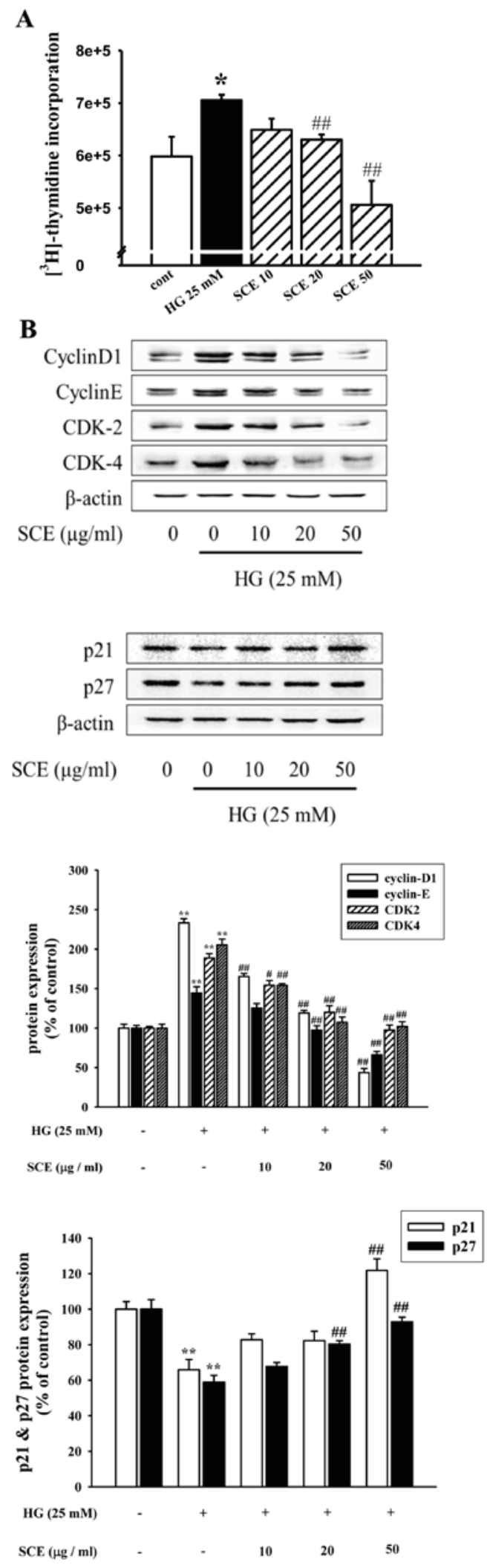

Figure 1. Effects of SCE on renal mesangial cell proliferation. (A) Mesangial cells were treated with various concentrations of SCE $(0,10,20$ and $50 \mu \mathrm{g} / \mathrm{ml}$ ) and $25 \mathrm{nM}$ D-glucose (HG) for $24 \mathrm{~h}$. Mesangial cell proliferation was measured by using the $\left[{ }^{3} \mathrm{H}\right]$-thymidine incorporation assay. Results are expressed as the mean \pm standard error of the mean from three independent experiments. ${ }^{*} \mathrm{P}<0.05$ vs. control; ${ }^{\# \#} \mathrm{P}<0.01$ vs. HG alone. (B) Inhibitory effect of SCE on protein expression of cell cycle related factors. Cells were incubated with SCE with or without HG (25 mM). After $24 \mathrm{~h}$, proteins were analyzed by western blot analysis. SCE, samchuleum; HG, high glucose; CDK, cyclin-dependent kinase; cont, control. 
$\mathbf{A}$
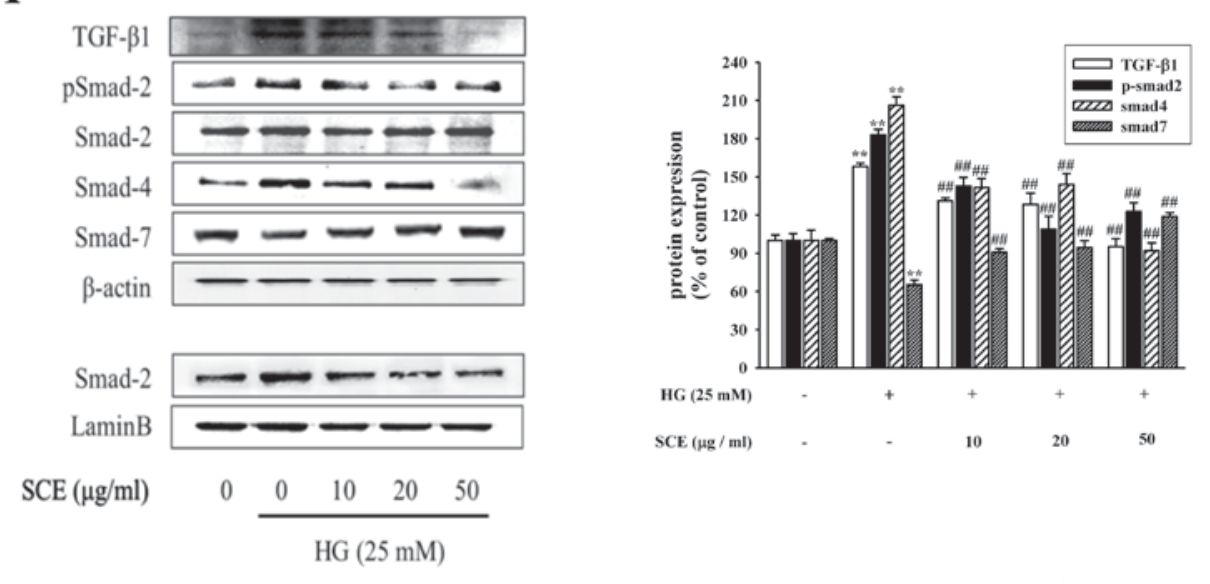

B
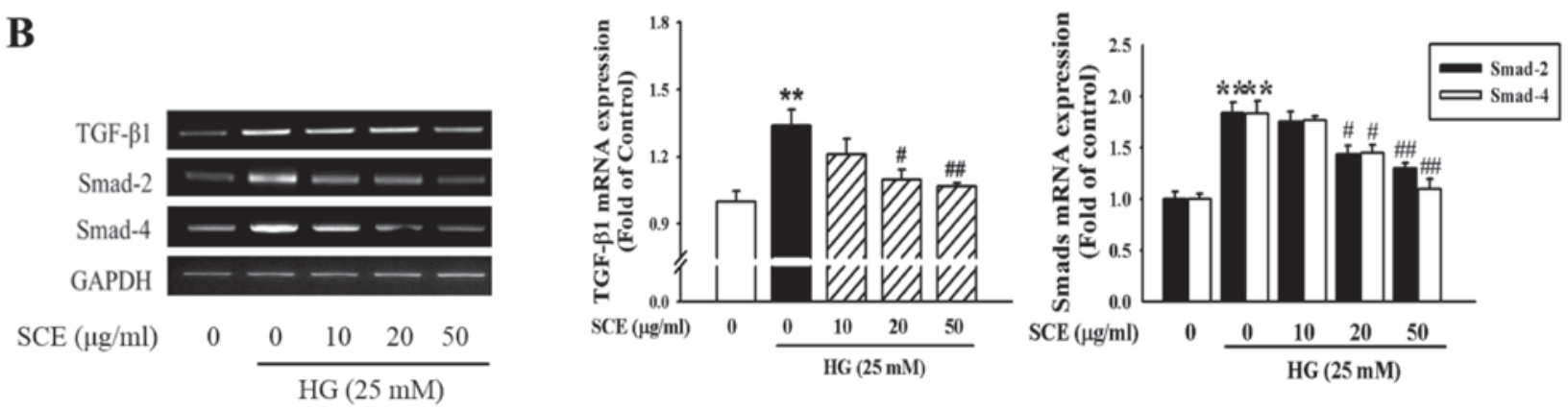

Figure 2. Effects of SCE on the expression levels of TGF- $\beta 1$ and Smad proteins. (A) Western blot analysis with specific antibodies against TGF- $\beta 1$, p-Smad-2, Smad-2, Smad-4 and Smad-7. $\beta$-actin and lamin B were used as the loadng controls for cytoplasmic and nuclear protein expression, respectively. (B) Levels of TGF- $\beta 1$, Smad- 2 and Smad-4 mRNA were analyzed by electrophoresis using $1 \%$ agarose gel and visualized by ethidium bromide staining. Each value represents the mean \pm standard error of the mean of three independent experiments. GAPDH was used as the internal control. ${ }^{* *} \mathrm{P}<0.01 \mathrm{vs}$. control; ${ }^{\#} \mathrm{P}<0.05$, ${ }^{\# \#} \mathrm{P}<0.01$ vs. HG alone. SCE, samchuleum; TGF- $\beta 1$, transforming growth factor b1; HG, high glucose; p, phosphorylated.

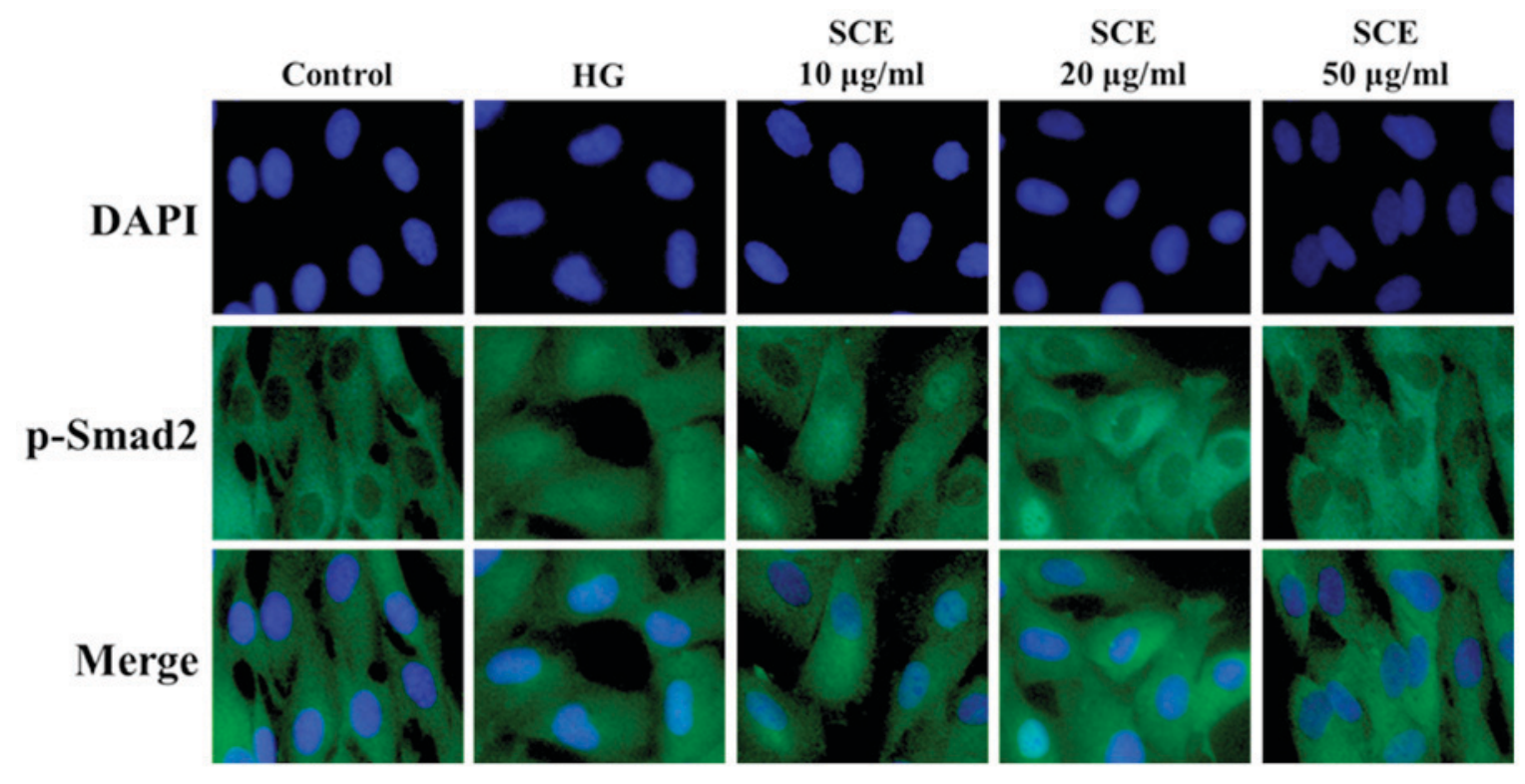

Figure 3. Effects of SCE on p-Smad-2 nuclear translocation. The expression of p-Smad-2 translocated into the nucleus analyzed by immunofluorescence microscopy (magnification, x400). Nuclei were stained with DAPI (blue) and p-Smad-2 was indicated by staining with Alexa Fluor 488 (green). Respective data were obtained from three independent experiments. SCE, samchuleum; p, phosphorylated; HG, high glucose.

cytoplasm of control cells, whereas HG stimulation caused an increase in p65 staining level in the nucleus. Pretreatment with SCE resulted in a decrease in nuclear p65 expression levels (Fig. 5B). 
A

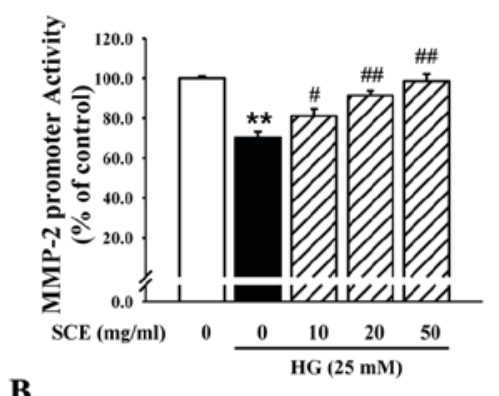

B
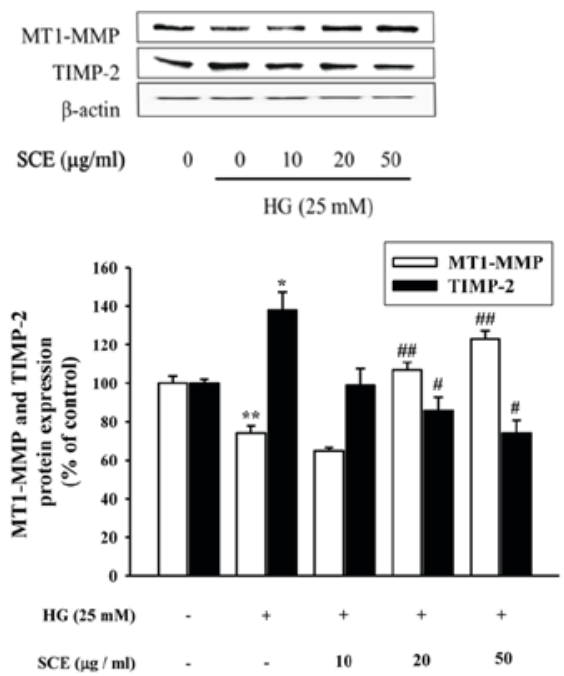

C

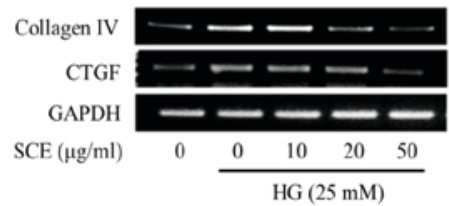

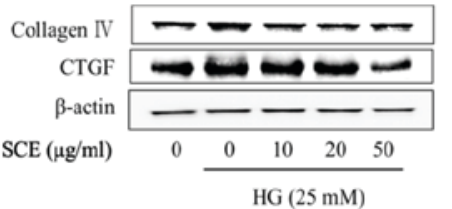

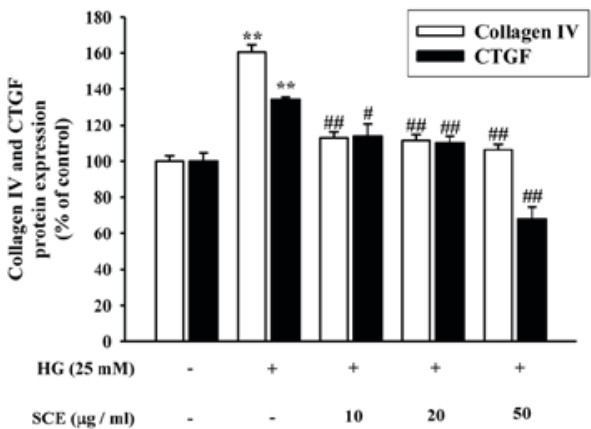

Figure 4. Effects of SCE on MMP and ECM under HG treatment. Cells were treated with HG (25 mM) with or without pretreatment with SCE (10, 20 and $50 \mu \mathrm{g} / \mathrm{ml}$ ). (A) Effect of SCE on MMP-2 promoter activity and the expression of MMP-2 protein under HG stimulation. Cells were transfected with an MMP-2-promoter-luciferase reporter plasmid and reported activity was normalized with the Renilla activity and expressed as a percentage of the control. ${ }^{*} \mathrm{P}<0.05,{ }^{* *} \mathrm{P}<0.01$ vs. control; ${ }^{\#} \mathrm{P}<0.05,{ }^{\# \#} \mathrm{P}<0.01$ vs. HG alone. (B) Effects of SCE on collagen IV, CTGF, MMP and TIMP protein expression levels. (C) Effects of SCE on collagen IV and CTGF mRNA expression levels. SCE, samchuleum; MMP, matrix metalloproteinase; ECM, extracellular matrix; HG, high glucose; MT1-MMP, membrane-bound type 1 MMP; CTGF, connective tissue growth factor; TIMP, tissue inhibitor of MMP.

ROS are known to activate a number of transcription factors as a common second messenger in various $\mathrm{NF}-\kappa \mathrm{B}$ activated pathways (28). Therefore, intracellular ROS production was measured to verify whether SCE exposure causes a decrease in the levels of HG-induced oxidative stress in renal mesangial cells (Fig. 6). HG increased ROS production (1.31 fold of control) compared with the control group. However, pretreatment with 20 and $50 \mu \mathrm{g} / \mathrm{ml} \mathrm{SCE}$ decreased the HG-induced production of ROS to 1.14 and 1.08 fold, respectively $(\mathrm{P}<0.05$ and $\mathrm{P}<0.01)$. Pretreatment with NAC $(1 \mathrm{mM})$, a potent antioxidant, reduced the HG-induced ROS production.

$\mathrm{NF}-\kappa \mathrm{B} / \mathrm{ROS}$ signaling may be involved in diabetes-associated renal mesangial inflammation. The results of the present study suggested that SCE treatment may suppress HG-induced renal mesangial inflammatory response through the disruption of the MCP-1, ICAM-1 and NF- $\kappa$ B/ROS signaling pathways.

\section{Discussion}

In the present study, in vitro human renal mesangial cell cultures were used to demonstrate that SCE pretreatment inhibited HG-induced renal fibrosis and inflammation. SCE exposure also suppressed renal hyperplasia and ECM accumulation by inhibiting the expression of TIMP-2 in the matrix-degrading MMP system. Development of DN is characterized by early-stage increases in cell proliferation and ECM expansion (29). Cell proliferation is controlled by cell cycle regulator proteins, which are necessary for progression through the cell cycle. The present study performed $\left[{ }^{3} \mathrm{H}\right]$-thymidine incorporation experiments to demonstrate that SCE pretreatment suppressed the HG-induced mesangial cell proliferation. SCE treatment inhibited the expression of proteins participating in CDK complexes (cyclin D1/CDK-4 and cyclin E/CDK-2) and increased the expression of CDK 
A

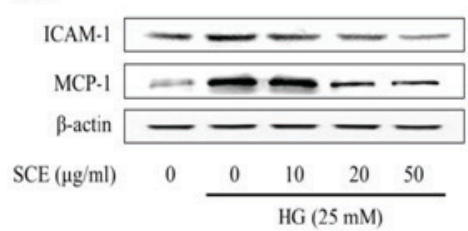

B
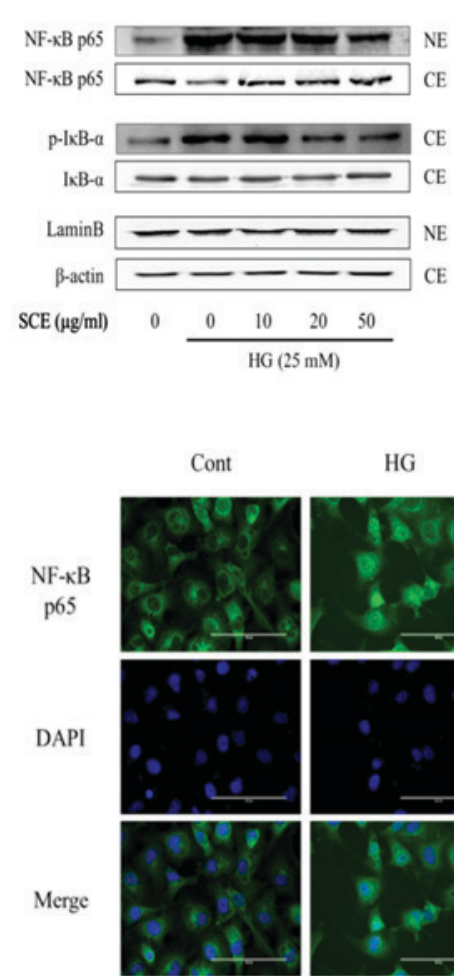

HG
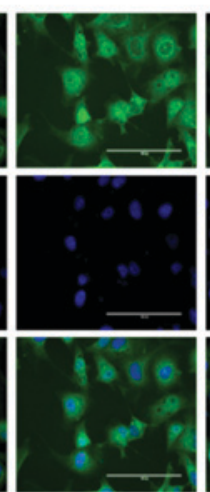

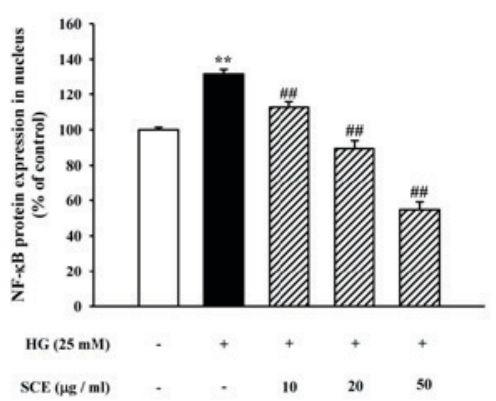

SCE
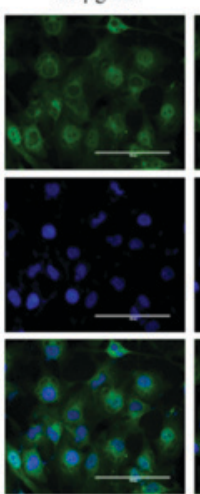
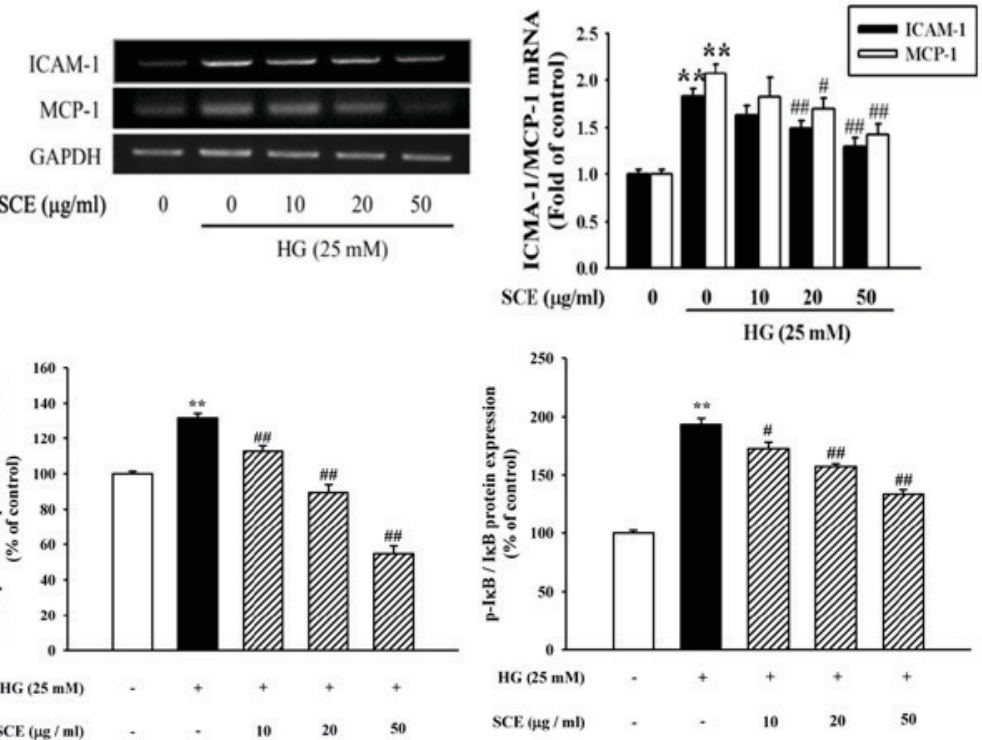

Figure 5. Effects of SCE on HG-induced renal inflammation. (A) Cells were treated with HG ( $25 \mathrm{mM})$ with or without SCE pretreatment $(10,20 \mathrm{and} 50 \mu \mathrm{g} / \mathrm{ml})$. ICAM-1 and MCP-1 expression was analyzed by western blot, PCR and reverse transcription-quantitative PCR. ${ }^{* *} \mathrm{P}<0.01$ vs. control; ${ }^{\#} \mathrm{P}<0.05$, ${ }^{\# \#} \mathrm{P}<0.01$ vs. HG alone. $\beta$-actin and GAPDH were used as internal controls. (B) Effects of SCE on the translocation of NF- $\mathrm{kB}$ subunit p65 into the nucleus. Cells were incubated with $10-50 \mu \mathrm{g} / \mathrm{ml} \mathrm{SCE}$ for $1 \mathrm{~h}$ prior to HG treatment. Nuclear and cytoplasmic proteins were isolated and analyzed by western blot assay using primary

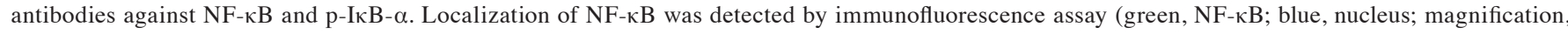
$\mathrm{x} 400$ ). Respective western blot data were obtained from three independent experiments. SCE, samchuleum; HG, high glucose; ICAM, intercellular adhesion molecule; MCP, monocyte chemotactic protein; PCR, polymerase chain reaction; NF, nuclear factor; I, inhibitor; p, phosphorylated; NE, nuclear extract; CE, cytoplasmic extract; cont, control.

inhibitors, $\mathrm{p} 21^{\mathrm{waf} 1 / \mathrm{cip} 1}$ and $\mathrm{p} 27^{\mathrm{kip} 1}$ under HG conditions. The results of the present study demonstrated that SCE had an inhibitory effect on mesangial proliferation by blocking the cell cycle in the $\mathrm{G}_{0} / \mathrm{G}_{1}$ to $\mathrm{S}$ phase and inhibiting DNA synthesis.

Mesangial ECM components, including fibronectin and type IV collagen, serve an active role as a structural support for the glomerular capillary tuft. They affect renal cell adhesion, growth, migration and proliferation (30). The results of the present study suggested that type IV collagen and CTGF, a profibrotic cytokine, may be involved in the ECM-synthesizing process, and their mRNA and protein expression levels were decreased following treatment with SCE. In addition, SCE was demonstrated to improve the HG-triggered dysfunction of the MMP system, via enhancing the expression of the ECM-degrading MT1-MMP and inhibiting TIMP-2 expression. In addition, the present results suggested that SCE may inhibit HG-induced mesangial proliferation and fibrosis through the regulation of MMP-2, which has been reported to induce the enzymatic breakdown of ECM (31). In mesangial cells, TGF- $\beta /$ Smad signaling is hypothesized to serve a significant role in the process of ECM accumulation and mesangial expansion. HG-induced mesangial cell hypertrophy has been associated with TGF- $\beta$ signaling in DN $(16,31,32)$.

The present study demonstrated that SCE pretreatment decreased the mRNA and protein expression levels of TGF- $\beta 1$, p-Smad-2 and Smad-4, but increased the expression levels of Smad-7 in HG conditions. In addition, p-Smad-2 was mainly expressed in the cytoplasm of normal mesangial cells; HG treatment promoted the nuclear translocation of p-Smad-2, whereas SCE pretreatment inhibited p-Smad-2 expression and its nuclear translocation. Thus, these results suggested that SCE has the capacity to block HG-induced renal fibrosis through the inhibition of factors associated with ECM accumulation and TGF- $\beta /$ Smad signaling in DN.

Kidney inflammation is associated with the progression of DN and understanding the inflammatory processes in renal 

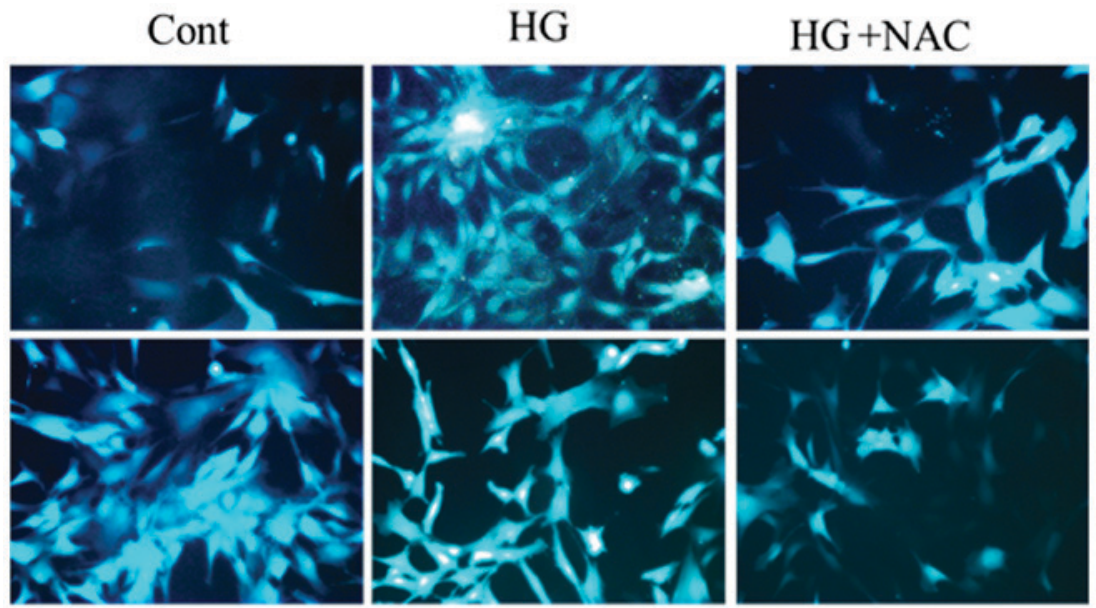

HG

HG

+SCE 10

+SCE 20

HG

+ SCE 50

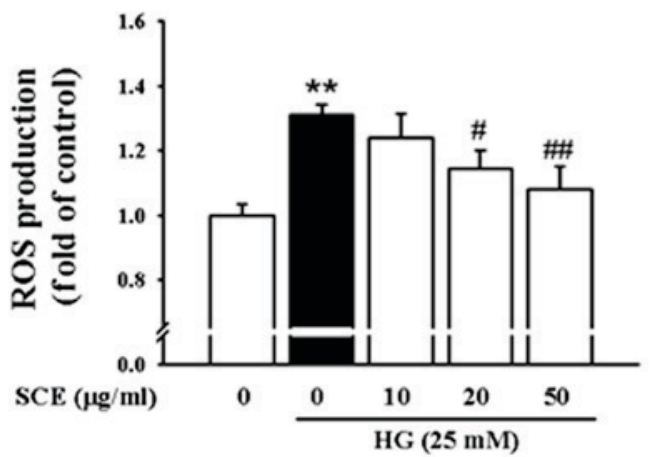

Figure 6. Effects of SCE on HG-induced intracellular ROS production. Renal mesangial cells were treated with HG in the absence or pretreatment of SCE and then treated with 2',7'-dichlorofluorescin diacetate. NAC was used as positive control. Data are represented as the mean \pm standard error of the mean of more than three independent experiments. ${ }^{* *} \mathrm{P}<0.01$ vs. control; $\mathrm{P}<0.05,{ }^{\# /} \mathrm{P}<0.01$ vs. HG alone. SCE, samchuleum; HG, high glucose; ROS, reactive oxygen species; NAC, N-acetyl-L-cysteine; cont, control.

fibrosis is necessary to aid the development of new therapeutics to halt the development of renal injury. In diabetes, the activated $\mathrm{NF}-\kappa \mathrm{B}$ translocates into the nucleus and induces the expression of activators and target genes of $\mathrm{NF}-\kappa \mathrm{B}$, including ICAM-1 and MCP-1, which in turn enhanced inflammation and finally lead to the acceleration of the pathogenesis of glomerulosclerosis and renal fibrosis through ECM accumulation $(33,34)$. The present study revealed that $\mathrm{HG}$ exposure enhanced ICAM-1 and MCP-1 protein and mRNA expressions, which were inhibited by pretreatment with SCE. In addition, $\mathrm{SCE}$ treatment not only reduced $\mathrm{HG}$-caused $\mathrm{NF}-\kappa \mathrm{B}$ subunit p65 translocation into the nucleus, but also inhibited the phosphorylation of I $\mathrm{B}-\alpha$ in the cytoplasm. Pretreatment with SCE also significantly suppressed HG-induced ROS production and consequently inhibited mesangial cell proliferation and inflammation. Results from the present study suggest that SCE may control renal inflammation by regulating the expression of inflammation-related genes and the NF- $\mathrm{B} / \mathrm{ROS}$ signaling pathway.

In conclusion, SCE pretreatment suppressed HG-inflamed mesangial proliferation and ECM accumulation by activating the matrix-degrading MMP system. SCE inhibited the induction of CTGF and type IV collagen, through the regulation of the TGF- $\beta /$ Smad pathway. SCE exposure also inhibited the mesangial inflammation possibly involved in renal fibrotic process. Thus, SCE may be able to improve diabetic kidney disease by disturbing TGF- $\beta /$ Smad and NF- $\mathrm{NB} / \mathrm{ROS}$ signaling pathways. These data provide the initial evidence that SCE treatment may be a new approach for the prevention and treatment of DN.

\section{Acknowledgements}

The present study was supported by the National Research Foundation of Korea (NRF) Grants funded by the Korean government (grant no. NRF-2017R1A5A2015805) and the Ministry of Education (grant no. NRF-2014R1A1A2008743).

\section{References}

1. Kolset SO, Reinholt FP and Jenssen T: Diabetic nephropathy and extracellular matrix. J Histochem Cytochem 60: 976-986, 2012.

2. Mason RM and Wahab NA: Extra-cellular matrix metabolism in diabetic nephropathy. J Am Soc Nephrol 14: 1358-1373, 2003.

3. Abrass CK, Peterson CV and Raugi GJ: Phenotypic expression of collagen types in mesangial matrix of diabetic and non-diabetic rats. Diabetes 37: 1695-1702, 1988

4. Mauer SM, Steffes MW, Ellis EN, Sutherland DE, Brown DM and Goetz FC: Structural-functional relationships in diabetic nephropathy. J Clin Invest 74: 1143-1155, 1984. 
5. Ziyadeh FN, Sharma K, Ericksen M and Wolf G: Stimulation of collagen gene expression and protein synthesis in murine mesangial cells by high glucose is mediated by autocrine activation of transforming growth factor-beta. J Clin Invest 93: 536-542, 1994.

6. Young BA, Johnson RJ, Alpers CE, Eng E, Gordon K, Floege J, Couser WG and Seidel K: Cellular events in the evolution of experimental diabetic nephropathy. Kidney Int 47: 935-944, 1995.

7. Kuan CJ, al-Douahji M and Shankland SJ: The cyclin kinase inhibitor p21WAF1, CIP1 is increased in experimental diabetic nephropathy: Potential role in glomerular hypertrophy. J Am Soc Nephrol 9: 986-993, 1998.

8. Adler S: Structure-function relationships associated with extracellular matrix alterations in diabetic glomerulopathy. J Am Soc Nephrol 5: 1165-1172, 1994.

9. Huang K, Liu W, Lan T, Xie X, Peng J, Huang J, Wang S, Shen X, Liu $\mathrm{P}$ and Huang $\mathrm{H}$ : Berberine reduces fibronectin expression by suppressing the S1P-S1P2 receptor pathway in experimental diabetic nephropathy models. PLoS One 7: e43874, 2012.

10. Köppel H, Riedl E, Braunagel M, Sauerhoefer S, Ehnert S, Godoy P, Sternik P, Dooley S and Yard BA: L-carnosine inhibits high-glucose-mediated matrix accumulation in human mesangial cells by interfering with TGF- $\beta$ production and signalling. Nephrol Dial Transplant 26: 3852-3858, 2011.

11. Pozzi A, Voziyan PA, Hudson BG and Zent R: Regulation of matrix synthesis, remodeling and accumulation in glomerulosclerosis. Curr Pharm Des 15: 1318-1333, 2009.

12. Abboud HE: Mesangial cell biology. Exp Cell Res 318: 979-985, 2012.

13. McLennan SV, Fisher EJ, Yue DK and Turtle JR: High glucose concentration causes a decrease in mesangium degradation. A factor in the pathogenesis of diabetic nephropathy. Diabetes 43 : 1041-1045, 1994.

14. Bernardo MM and Fridman R: TIMP-2 (tissue inhibitor of metalloproteinase-2) regulates MMP-2 (matrix metalloproteinase-2) activity in the extracellular environment after pro-MMP-2 activation by MT1 (membrane type 1)-MMP. Biochem J 374 739-745, 2003

15. McLennan SV, Wang XY, Moreno V, Yue DK and Twigg SM: Connective tissue growth factor mediates high glucose effects on matrix degradation through tissue inhibitor of matrix metalloproteinase type 1: Implications for diabetic nephropathy. Endocrinology 145: 5646-5655, 2004.

16. Sharma K and Ziyadeh FN: Hyperglycemia and diabetic kidney disease: The case for transforming growth factor-beta as a key mediator. Diabetes 44: 1139-1146, 1995.

17. Ask K, Bonniaud P, Maass K, Eickelberg O, Margetts PJ, Warburton D, Groffen J, Gauldie J and Kolb M: Progressive pulmonary fibrosis is mediated by TGF-beta isoform 1 but not TGF-beta3. Int J Biochem Cell Biol 40: 484-495, 2008.

18. Massagué J, Seoane J and Wotton D: Smad transcription factors. Genes Dev 19: 2783-2810, 2005.

19. Derynck R and Zhang YE: Smad-dependent and Smad-independent pathways in TGF-beta family signaling. Nature 425: $577-584,2003$
20. Fornoni A, Ijaz A, Tejada T and Lenz O: Role of inflammation in diabetic nephropathy. Curr Diabetes Rev 4: 10-17, 2008.

21. Clavreul N, Sansilvestri-Morel P, Magard D, Verbeuren TJ and Rupin A: (Pro)renin promotes fibrosis gene expression in HEK cells through a Nox4-dependent mechanism. Am J Physiol Renal Physiol 300: F1310-F1318, 2011.

22. Bondar IA, Klimontov VV and Nadeev AP: Urinary excretion of proinflammatory cytokines and transforming growth factor beta at early stages of diabetic nephropathy. Ter Arkh 80: 52-56, 2008 (In Russian).

23. Livak KJ, Schmittgen TD: Analysis of Relative Gene Expression Data Using Real-Time Quantitative PCR and the 22DDCT Method. METHODS, 25:402-8, 2001.

24. Michelini E, Cevenini L, Mezzanotte L, Ablamsky D, Southworth T, Branchini B, Roda A: Spectral-resolved gene technology for multiplexed bioluminescence and high-content screening. Anal Chem, 80:260-7, 2008.

25. Kang SW, Choi JS, Choi YJ, Bae JY,Li J: Licorice isoliquiritigenin dampens angiogenic activity via inhibition of MAPK-responsive signaling pathways leading to induction of matrix metalloproteinases. J Nutr Biochem, 21:55-65, 2010.

26. Okada S, Shikata K, Matsuda M, Ogawa D, Usui H, Kido Y, et al: Intercellular adhesion molecule-1-deficient mice are resistant against renal injury after induction of diabetes. Diabetes, 52:2586-93, 2003.

27. Poljakovic M, Nygren JM, Persson K: Signalling pathways regulating inducible nitricoxide synthase expression in human kidney epithelial cells. Eur J Pharmacol, 469:21-8, 2003.

28. Ha H, Lee HB: Oxidative stress in diabetic nephropathy: Basic and clinical information. Curr Diab Rep, 1:282-7, 2001.

29. Mahadevan P, Larkins RG, Fraser JR, Dunlop ME: Effect of prostaglandin E2 and hyalurunan on mesangial cell proliferation: A potential contribution to glomerular hypercellularity in diabetes. Diabetes, 45:44-50, 1996.

30. Pozzi A, Voziyan PA, Hudson BG, Zent R. Regulation of matrix synthesis, remodeling and accumulation in glomerulosclerosis. Curr Pharm Des, 15: 1318-33, 2005.

31. Park IS, Kiyomoto H, Abboud SL, Abboud HE: Expression of transforming growth factor- $\beta$ and type IV collagen in early streptozotocin-induced diabetes. Diabetes, 46:473-80, 1997.

32. Huse M, Muir TW, Xu L, Chen YG, Kuriyan J, Massague J: The TGF $\beta$ receptor activation process: Aan inhibitor- to substratebinding switch. Mol Cell, 8:671- 82, 2001.

33. Ohga S, Shikata K, Yozai K, Okada S, Ogawa D, Usui H: Thiazolidinedione ameliorates renal injury in experimental diabetic rats through anti-inflammatory effects mediated by inhibition of NF- $x$ B activation. Am J Physiol, 292:F1141-50, 2007.

34. Yin D, Yao W, Chen S, Hu R, Gao X: Salidroside, the main active compound of Rhodiola plants, inhibits high glucose-induced mesangial cell proliferation. Planta Med, 75: 1191-5, 2009. 